\title{
Energy Flows Management of Multiple Electric Vehicles in Smart Grid
}

\author{
Gergana Vacheva ${ }^{1}$, Nikolay Hinov ${ }^{1}$, Hristiyan Kanchev ${ }^{1}$, Rad Stanev $^{2}$, Octavian Cornea ${ }^{3}$ \\ ${ }^{I}$ Department of Power Electronics, Technical University of Sofia, \\ Sofia, Bulgaria \\ ${ }^{2}$ Electrical Power Engineering Department, Technical University of Sofia, \\ Sofia, Bulgaria \\ ${ }^{3}$ Department of Electrical Engineering, Politechnical University of Timisoara, \\ Romania \\ gergana_vacheva@tu-sofia.bg
}

\begin{abstract}
This paper presents energy flows management of multiple electric vehicles charging and its impact on a microgrid. The studied low voltage grid comprises also two photovoltaic generators and non-dispatchable loads. Three concepts using electric vehicles batteries as a distributed storage and bidirectional energy transfer in the Smart Grid are considered: Vehicle to Home, Vehicle to Vehicle and Vehicle to Grid. The potential for implementation of flexible microgrid energy flow management strategy for reduction of peaks in power consumption, absorption or production of reactive power (when required) and improving the power quality in the studied microgrid are estimated. For this purpose a set of usual load profiles of electric vehicle charging modes are studied and presented. Simulation results demonstrate the potential of electric vehicles as a flexible load and energy storage for peak load shaving in microgrids.
\end{abstract}

Index Terms-Battery storage devices; Energy flows; Electric vehicle; Smart micro grids; State of charge.

\section{INTRODUCTION}

Recently the number of the electric vehicles (EV) is increasing and in a decade they will probably outnumber the vehicles with internal combustion engine. In such a case it is possible that simultaneous operation of multiple EV charge stations at the same node could be a challenge for the low voltage distribution network stability. The simultaneous charging of multiple EV's could result in a significant total load. This could pose a problem to grid dispatching, because the majority of distribution grids are not designed for such load peaks. Thus, the topics related to the cumulative influence of multiple EV charge profiles on small-scale distribution grids and the control of energy flows are of significant interest to researchers in this domain. Unidirectional charging only consumes power and cannot provide grid support by grid feeding for reduction of potential grid congestions. In case of bidirectional charging

Manuscript received 27 February, 2018; accepted 2 October, 2018.

This research is funded in the framework of project ,Gestion intelligente des flux énergétiques dans des micro- et nano-réseaux" funded by Agence Universitaire de la Francophonie and the Bulgarian National Fund for Scientific Research. devices, EV's are capable to feed in power back to the grid Moreover, the bidirectional chargers can provide reactive power to the grid and play a role of energy storage device in grids with distributed generation. The growing number of EV's increases the chance of overload in distribution grids which might lead to difficulties in grid dispatching and power system management.

Several technologies for management of EV's exist: Recently, the following concepts are being implemented by electric vehicle manufacturers: Vehicle to Home (V2H), Vehicle to Vehicle (V2V) and Vehicle to Grid (V2G) [1].

- The usage of $\mathrm{V} 2 \mathrm{H}$ allows connection of EV to the domestic grid by single- or three-phase converters located in the vehicle itself (on-board) or off-board. The converters can also be unidirectional or bidirectional. This technology gives an opportunity to exchange energy with the local grid.

$-\mathrm{V} 2 \mathrm{~V}$ allows exchange of power between multiple electric vehicles connected to a microgrid. This could be performed through local aggregators that coordinate the energy exchanged among a group of EV's. The aggregator controls and adjusts the defined power references of the EV chargers.

- V2G allows the power flow between EV's and the distribution network in both directions. The control system adjusts the charge/discharge power references according to signals from the local aggregator.

The objective of this paper is a study and optimal management of energy flows in a microgrid with distributed generation and multiple electric vehicles with bidirectional chargers. For this purpose, the possible use of EV batteries as energy storage for flattening the cumulative load curve is considered.

\section{STRUCTURE OF THE SySTEM STUdIED}

The micro and nanogrids are hybrid systems commonly including renewable energy sources, energy storage devices, conventional generators (based on internal combustion engine or micro gas turbines) or other generation. These are able to operate autonomously or connected to the 
distribution grid. In some Smart Grid concepts, decentralized production and consumption in microgrids are managed locally using aggregators for each microgrid. The microgrid aggregators coordinate the dispatching of generators, storage devices and loads and exchange load and generation data and forecasts among them and the Distribution System Operator (DSO). In this way a local group of decentralized generators and loads can be considered by the distribution and transmission network operators as a single entity that behaves as a consumer or a producer of electric energy which can be dispatched. In this way, load forecasting, dispatching and coordinated actions of all participants in the power system can be optimized, which could lead to optimal operation of the entire system.

A common and representative structure is described in this paper (Fig. 1).

The PV inverter transforms the continuous current produced by the PV modules into alternating current injected into the grid (Fig. 1). A key point in inverter design is the DC/AC conversion efficiency. The most common PV system topologies are the following:

- Centralized system: a single inverter sized according to the total peak power: the most suitable option for smallscale installations (up to tens of $\mathrm{kW}$ ).

- Modular system: several inverters are connected to the AC grid in parallel. This structure is preferred for largescale PV systems and in systems with multiple arrays subject to different conditions (shading, orientation etc.).

- Inverters built into the PV modules (microinverters) this topology is used mainly for micro-scale PV systems with a few modules.

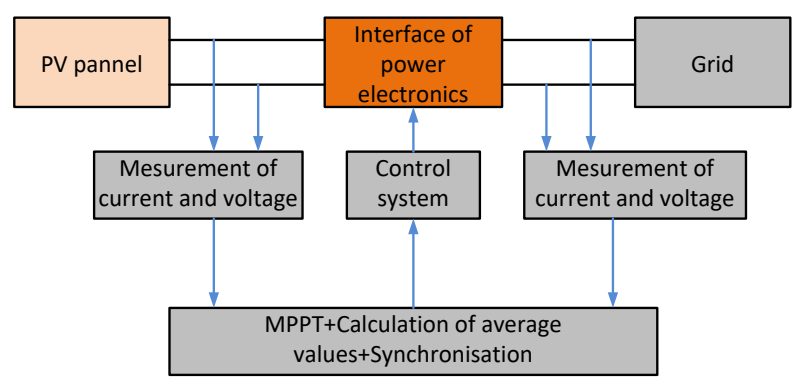

Fig. 1. General structure of a PV system.

\section{A. Modelling of the EVs and Microgrid}

Nowadays several techniques and methodologies for modelling of EVs and microgrids with distributed generation are present in literature [2], [3]. In a system of small scale, with several branches, the classical analysis of power flows can provide a solution to the given problem with adequate precision and at the cost of admissible computational time. Although the EV charging is theoretically stochastic in its inherent some limitations based on the availability of the electric vehicles can be considered since their usage and charging follows namely different patterns in weekdays and in the weekend. Although different, those patterns are individually repetitive.

The exact modelling of the loads and PV generation element by element seems to be a complex and computationally demanding task. Additionally, the EV charging includes some complex features imposed by the battery, power electronics and control system behaviour which further complicate the problem. At the same time adequate computational times are needed for simulations of long-term dispatching and operation of the grid. For this reason, a generalized deterministic mathematical model based on the PV production, EV and domestic load forecasts is proposed in this paper. Although simplified, the model can provide sufficient accuracy, which is needed for improvement of the control system in microgrids with EV, distributed generation and storage. The following equations describe the power flows for the different technologies for EV charging (V2H, V2V and V2G):

$$
\begin{gathered}
P_{t}^{L}+\sum_{n=1}^{N} P_{t, n}^{G} \leq P_{t, \max }^{H}, \\
\sum_{n=1}^{K} \eta_{n}^{G} P_{t, n}^{G}=0, \\
P_{t}^{L}+\sum_{n=1}^{N+K} \eta_{n}^{G} P_{t, n}^{G}=P_{t}^{P S},
\end{gathered}
$$

where $t=1 \sim T, T$ - the time period, $N$ - the number of EVs at home, $K$ - the number of EVs, $P_{t}^{L}-$ power of loads, $P_{t, n}^{G}$ - output power, $P^{P S}{ }_{t}$ - power at the point of common coupling, $P^{H}{ }_{t, \max }-$ maximum power of the system, $\eta_{n}{ }^{G}-$ efficiency of power conversion.

Figure 2 presents the structure of the studied microgrid - a three-phase low-voltage distribution network with 21 nodes located in a small residential district in Bulgaria, region of Sofia [4]. The consumed power is symmetrical in all phases and the loads are predominantly active (power factor correction of all loads is considered. The minimum and peak systems loads are respectively $P_{\text {min }}=31,1 \mathrm{~kW}$ and $P_{\max }=$ $115,6 \mathrm{~kW}$ without considering the load due to EV charging process.

At node 10 and 18 of the grid are connected PV generators. The first one has a peak power $P G 1=29,8 \mathrm{~kW}$, connected at node 10 and the second $-P G 2=51,5 \mathrm{~kW}$ (connected at node 18).

The values used for system analysis are: the magnitudes and phase angles of the voltages; the active and reactive powers exchanged. In the studied small-scale power system, the state of each node is described by the following equations [4]:

$$
\begin{gathered}
P_{k}=\sum_{m \in k} V_{k} V_{m}\left(G_{k m} \cos \theta_{k m}+B_{k m} \sin \theta_{k m}\right), \\
Q_{k}=\sum_{m \in k} V_{k} V_{m}\left(G_{k m} \sin \theta_{k m}-B_{k m} \cos \theta_{k m}\right), \\
\dot{Y}_{k m}=G_{k m}+j B_{k m}, \\
\theta_{k m}=\theta_{k}-\theta_{m},
\end{gathered}
$$

where $P_{k}$ and $Q_{k}$ are respectively the active and reactive powers in node $k ; V_{k}$ and $V_{m}$ are the voltage magnitudes in nodes $k$ and $m$ respectively; $\dot{Y}_{k m}$ is element with indexes $k$ and $m$ from the bus admittance matrix; $\theta_{k}$ and $\theta_{m}$ are the voltage angles at node $k$ and $m$ respectively. 


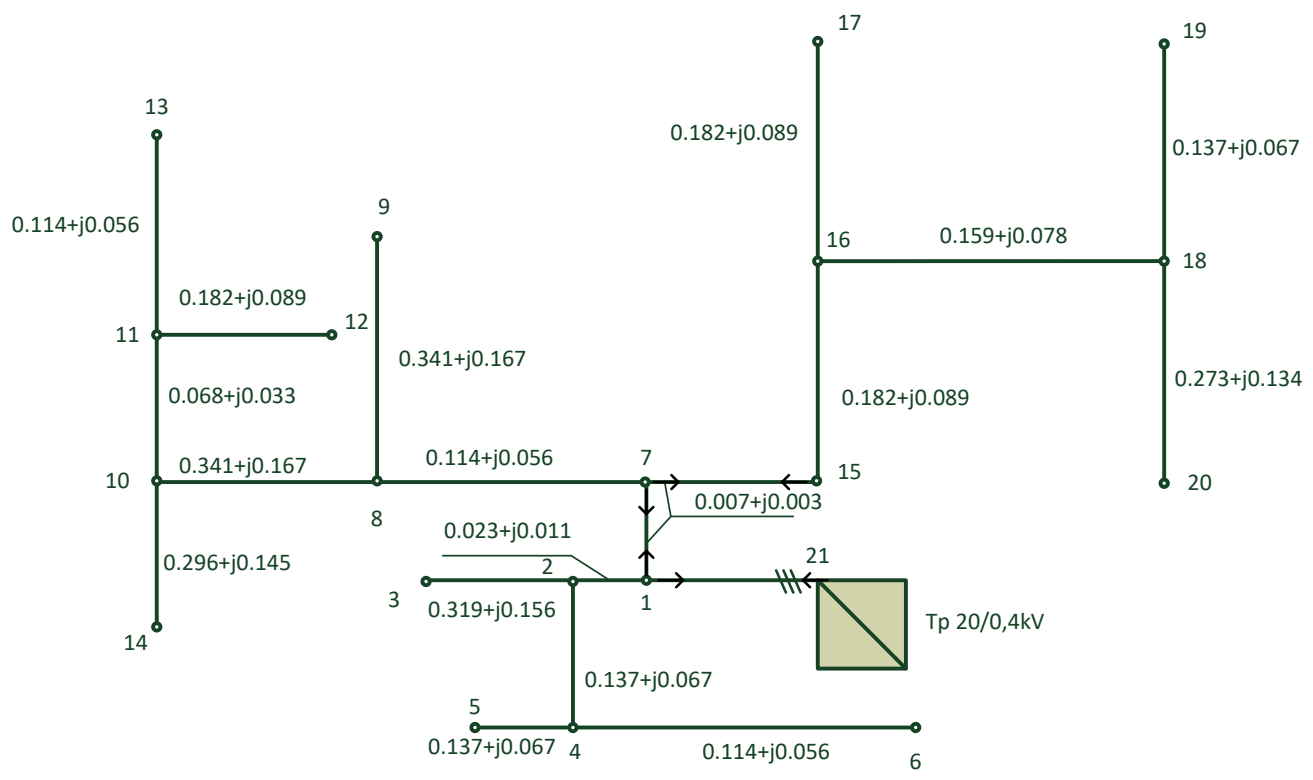

Fig. 2. Schematic representation of the studied microgrid.

\section{A. Different Charging Modes for EVs}

The main part of the common electric vehicle battery chargers are only designed for charging which represents unidirectional transfer of energy. These are able to provide high instantaneous power and efficiency of the conversion process at a low cost. Whereas for $\mathrm{V} 2 \mathrm{G}, \mathrm{V} 2 \mathrm{H}$ and $\mathrm{V} 2 \mathrm{~V}$ technologies implement a bidirectional converter, designed for on-board charging systems or charging stations. Table 1 presents some different types of standardized charging modes of electric vehicles.

TABLE I. DIFFERENT CHARGING MODES FOR EV.

\begin{tabular}{|c|c|}
\hline Charging mode & Power \\
\hline Normal charging & $3.7 \mathrm{~kW}$ single phase $(230 \mathrm{~V}-16 \mathrm{~A})$ \\
\hline Accelerated charging & $23 \mathrm{~kW}$ three phase $(400 \mathrm{~V}-32 \mathrm{~A})$ \\
\hline Fast charging & $43 \mathrm{~kW}$ three phase $(400 \mathrm{~V}-64 \mathrm{~A})$ \\
\hline Fast charging & $50 \mathrm{~kW}$ DC Mixed AC and DC \\
\hline
\end{tabular}

In this study two types of electric vehicles are considered: vehicle 1 is Mitsubishi i-MiEV and vehicle 2 - Nissan Leaf. Those vehicles are also chosen because their detailed characteristics and charging profiles (in normal and fast charge modes) can be found in various sources, including the documentation provided by their producers and in litterature [6]-[8]. The number of EV worldwide is expected to increase significantly in the following years [9]-[11]. Nevertheless, each model has a different charge profile, therefore in future studies it will be interesting to include and study a large number of different vehicles with normal and fast charge capabilities.

\section{B. Profiles of EV Charging}

On Fig. 3-Fig. 5 are depicted the charge profiles of both vehicles considered in this study. The power consumed for charging is presented as a function of their battery State Of Charge (SoC). Two charge modes are studied: normal and fast. The following equation describes the optimal SoC for the presented EVs

$$
\operatorname{SoC}_{n, \min } \leq \operatorname{SoC}_{t, n} \leq \operatorname{So} C_{n, \max } .
$$

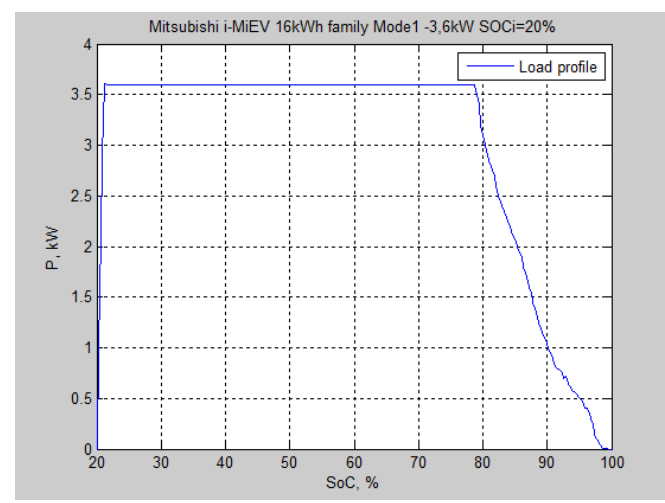

Fig. 3. Charging profile of vehicle 1 - normal charge $(3,6 \mathrm{~kW})$.

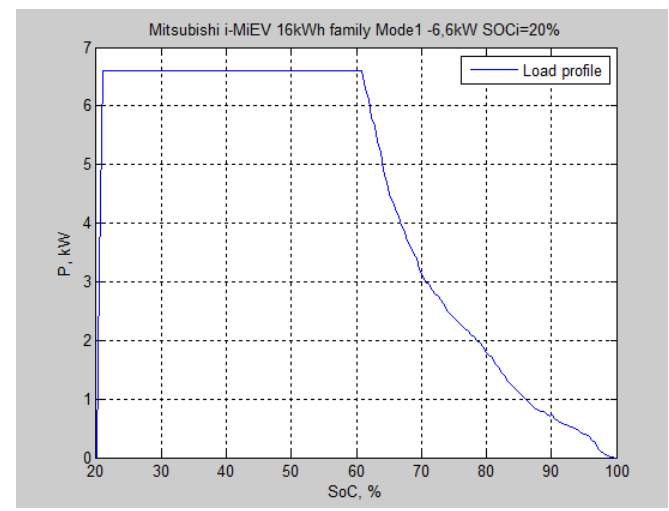

Fig. 4. Charging profile of vehicle 1 - fast charge $(6,6 \mathrm{~kW})$.

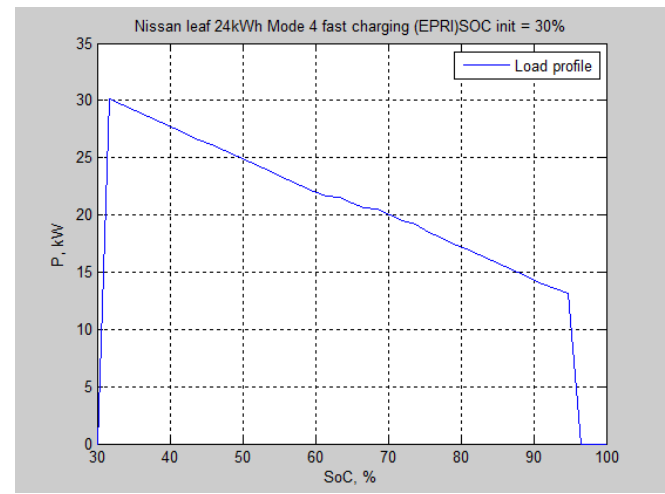

Fig. 5. Charging profile of vehicle 2 - fast charge ( $24 \mathrm{~kW})$. 


\section{LOAD PROFILE AND PV GENERATION PROFILES}

Based on the 24-hour grid load and PV generation forecasts (Fig. 6 and Fig. 7) and the characteristics presented on Fig. 3-Fig. 5, the optimal power references and charging time of considered vehicles can be determined.

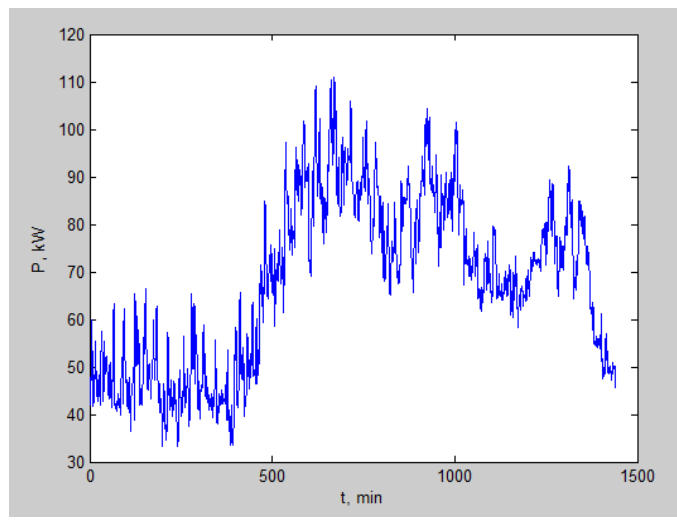

Fig. 6. Grid load forecast.

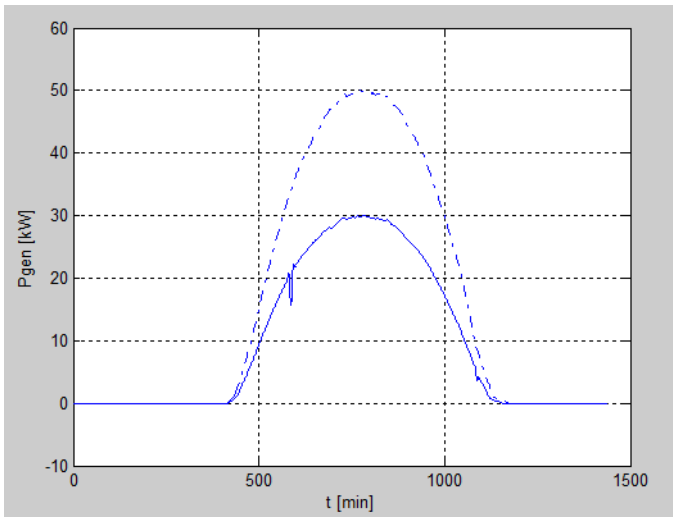

Fig. 7. PV generation forecast ( $P G 1$ - solid line, $P G 2$ - dashed line).

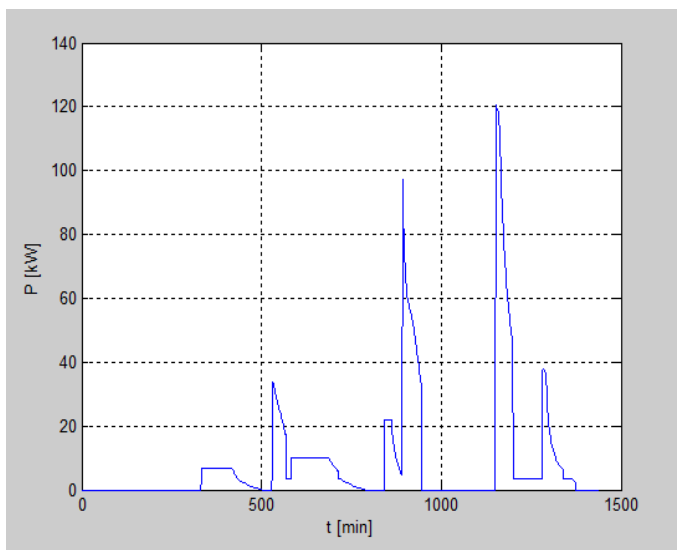

Fig. 8. Total grid load for the examined period with EV charging

Figure 6 presents the aggregated domestic load profile in the studied system. The load forecast does not include the presence of electric vehicles. The PV production forecast for an average summer day is depicted on Fig. 7 (PG1 - solid line, PG2 - dashed line). The forecasted values from those figures are used for assessment of grid stability. First, computations are performed without the presence of EV's.
After that the impact of EV charging on the grid is studied (Fig. 8).

\section{CONCLUSIONS}

An assessment and analysis of the energy flows in a lowvoltage distribution grid is presented in this paper. The studied system comprises two PV generators and multiple Electric Vehicles. In this study different technologies (V2H, $\mathrm{V} 2 \mathrm{~V}$ and $\mathrm{V} 2 \mathrm{G}$ ) for bidirectional power flow and control of EVs charging and discharging cycles are considered. Based on the EV charge profiles, sample load and PV generation curves, the time variation of grid parameters in various nodes of the grid is obtained. Results from this research might be further useful for research on different optimization techniques for energy flows management for multiple EV's in the Smart Grid. Based on this study, further researches including $\mathrm{EV}$ batteries and storage systems usage as dispatchable loads can be considered.

\section{REFERENCES}

[1] C. Liu, K. T. Chau, D. Wu, S. Gao, "Opportunities and challenges of vehicle-to-home, vehicle-to-vehicle, and vehicle-to-grid technologies", Proceedings of the IEEE, vol. 101, no. 11, pp. 24092427, 2013. DOI: 10.1109/JPROC.2013.2271951.

[2] F. X. Li, W. Qiao, H. B. Sun, H. Wan, J. H. Wang, Y. Xia, et al, "Smart transmission grid: vision and framework", IEEE Trans. Smart Grid, vol. 1, no. 2, pp. 168-177, 2010. DOI: 10.1109/TSG.2010.2053726.

[3] O. Malik, P. Havel, "Analysing demand-side management potential: Situation in Europe and the Czech Republic", in Proc. 2011 10th Int. Conf. Environment and Electrical Engineering (EEEIC), pp. 1-4, 2011. DOI: 10.1109/EEEIC.2011. 5874781.

[4] L. Pieltain Fernandez, T. Gomez San Roman, R. Cossent, C. Mateo Domingo, P. Frias, "Assessment of the impact of plug-in electric vehicles on distribution networks", IEEE Trans. Power Systems, vol. 26, no. 1, pp. 206-213, 2011. DOI 10.1109/TPWRS.2010.2049133.

[5] M. Datta, "Fuzzy logic based frequency control by V2G aggregators", in IEEE 5th Int. Symposium on Power Electronics for Distributed Generation Systems (PEDG 2014), Galway, Ireland, 2014, pp. 1-8. DOI: 10.1109/PEDG.2014.6878702

[6] J. A. P. Lopes, F. J. Soares, P. M. R. Almeida, "Integration of electric vehicles in the electric power system", Proceedings of the IEEE, vol. 99, no. 1, pp. 168-183, 2011. DOI: 10.1109/JPROC.2010.2066250.

[7] Y. Cao et al., "An optimized EV charging model considering TOU price and SOC curve", IEEE Trans. Smart Grid, vol. 3, no. 1, pp. 388-393, 2012. DOI: 10.1109/TSG.2011.2159630.

[8] A. G. Neagoe-Stefana, A. C. Neagoe, A. C. Mandis, "Impact of charging electric vehicles in residential grid on the power losses and voltage plan", in 2014 Int. Symposium on Fundamentals of Electrical Engineering (ISFEE 2014), Bucharest, Romania, 2014, pp. 1-4. DOI: 10.1109/ISFEE.2014.7050603.

[9] J. Wang, K. Wu, Z. Liu, F. Wang, Y. Zhao, "Impact of plug-in hybrid electric vehicles on power distribution networks", in Proc. of 4th International Conference on Electric Utility Deregulation and Restructuring and Power Technologies, 2011, pp. 1618-1622..

[10] S. Schey, D. Scoffield, J. Smart, "A first look at the impact of electric vehicle charging on the electric grid in the EV project", World Electric Vehicle Journal, vol. 5, no. 3, pp. 667-678, 2012. DOI: 10.3390/wevj5030667.

[11] C. Jin, J. Tang, P. Ghosh, "Optimizing electric vehicle charging with energy storage in the electricity market", IEEE Trans. Smart Grid, vol. 4, no. 1, pp. 311-320, 2013. DOI: 10.1109/TSG.2012.2218834. 